\title{
Samsun Azot Sanayii (TÜGSAŞ) ve Karadeniz Bakır İşletmeleri (KBi) Emisyonlarının Çevre Topraklarına Olan Etkileri*
}

\author{
Emine Erman KARA1 Ilknur AÇוKGÖZ1 Pelin GÜLTEKIN1 Havva KÜLAHLI ${ }^{1}$
}

Geliş Tarihi : 24.07.1997

\begin{abstract}
Özet: Bu araştırmada Ülkemizin Orta Karadeniz Coğrafi bölgesinde yer alan Samsun ilinde Samsun Azot Sanayii (TÜGSAŞ) ve Karadeniz Bakır Işletmeleri (KBl) baca emisyonlarının çevredeki tarım topraklarının bazı kimyasıl ve biyolojik özellikleri ile mikroelement kapsamlarına olan etkilerini belirlemek amaçlanmıştır. Bölgedeki hakim rüzgar yönü ve tarımsal alanların yayııma durumu dikkate alınarak üç ayrı doğrultuda alınan toprak örnekleri $0-5,5-10,10-20,20-40$, 40-60 ve $60-80 \mathrm{~cm}$ derinliklerden alınmıştır. Fabrika uzaklığı ile toprakların pH değerleri ve kireç içerikleri arasında bir ilişki olmadığı, derinlikle $\mathrm{pH}$ ve kireç içeriğinde düşme olduğu belirlenmiștir. Toprağın biyolojik altivitesini belirlemede kullanılan kriterlerinden $\mathrm{CO}_{2}$ üretimi ve dehidrogenaz (DHG) enzim aktivitesinde fabrikadan uzaklık ve yöne bağı olarak karakteristik bir dağııım olmadığı saptanmıştır. Ayrıca fabrikalara yakın kesimierde toprak yüzeyinde ağır metallerden $\mathrm{Fe}$, $\mathrm{Cu}, \mathrm{Zn}$ ve $\mathrm{Mn}$ birikimi olduğu ortaya konulmuştur.
\end{abstract}

Anahtar Kelimeler: Fabrika baca emisyonları, toprağın $\mathrm{CO}_{2}$ üretimi, dehidrogenaz (DHG) enzinı aktivitesi, ağır metal birikimi ( $\mathrm{Fe}, \mathrm{Cu}, \mathrm{Zn}, \mathrm{Mn})$

\section{The Effect of Chimney Emissions of Samsun Nitrogen Industry and Black Sea Copper Enterprise on The Surrounding Soil}

\begin{abstract}
The aim of this research is to determine the effects of the Chimney emission:s of Samsun Nitrogen Industry and Black Sea Copper Enterprise, established in Samsun, located in the Middle Black Sea Geographical Region, on some chemical and biological properties and microelement contens of the surrounding agricultural soil. Since wind direction and extension of agricultural lands have been considered, soil samples have been taken from $0-5,5-10$, $10-20,20-40,40-60$ and $60-80 \mathrm{~cm}$ depths in three different directions. It has been found out that there is no relatioriship between factory distance and $\mathrm{pH}$ values; and between factory distance and lime content, that $\mathrm{pH}$ values and lime content decreased in dephts. It has been determined that there is no characteristic distribution dependent upon direction and factory distance in $\mathrm{CO}_{2}$ production and dehydrogenase (DHG) activity, which are the criteria used in the determination of the biological activity of the soil. Besides, it has been brought out that there is heavy metal accumulation such as $\mathrm{Fe}, \mathrm{Cu}$, $\mathrm{Zn}, \mathrm{Mn}$, on the surface of the soil in the parts close to the factories.
\end{abstract}

Key Words: Factory chimney emissions, soil $\mathrm{CO}_{2}$ production, dehydrogenase activity, heavy metal accumulation $(\mathrm{Fe}, \mathrm{Cu}, \mathrm{Zn}, \mathrm{Mn}$ )

\section{Giriş}

Çevre kirliliği son yıllarda en güncel konulardan biri haline gelmiştir. Hava kirletici maddeler, solunum yolu ile canlılarda doğrudan zararlanma yapmaları yanında toprakta, bitkilerde birikmeleri nedeni ile dolaylı ve sürekli etkide bulunmaktadırlar. Bu etki ise özellikle endüstri bölgelerinde yoğunlaşmaktadır. Günümüz toplumunda tüketim ve hayat alışkanlıklarına, kentsel ve endüstriyel atıklara; tarımsal ve endüstriyel üretim tekniğine bağlı olarak ortaya çıkan organik ve inorganik zararlı maddeler çeşitli kaynaklardan katı, sıvı ve gaz formlarda hava, su ve toprağa ulaşabilmektedirler. Bu maddelerin zararlı olup olmadıkları ise esas olarak etki dozlarına bağlı bulunmaktadir.
Ekosistemler içerisinde topraklar, zararlı maddeleri bünyesine alıp tutan, zararlı maddelerin ve toprakların özelliklerine göre onları a:z yada çok doğadaki döngüsünden uzaklaştırabilen doğal filtreler olarak kabul edilmektedirler. Endüstriyel ve tarımsal faaliyetler sonucu açığa çıkan çeşitli maddeler artan dozlarda toprağa bulaşmaya başlamıştır. Toprak üzerindeki uygulamaların yanı sıra, hava ve su kirlerımesiyle topraklarda çeşitli sorunlar ortaya çıkmaktadır. E3u kirleticiler içerisinde ağır metaller, $\mathrm{SO}_{2}$ ve florlu gazlar başta gelmektedirler.

Endüstriyel ve kenisel kökenli gaz emisyonları ile tozumalar sonucu çeşitli kirleticiler toprak yüzeyine

\footnotetext{
* Bu araştırma Ondokuz Mayıs Üniv. Araştırma Fonu'nca desteklenmiştir.

${ }^{1}$ Ondokuz Mayıs Üniv. Ziraat Fak. Toprak Bölümü - Samsun
} 
KARA, E.E。 ve ark. "Samsun Azot Sanayii (TÜGSAŞ) ve Karadeniz Bakır Işletmesi (KBI) emisyonlarının çevre topraklarına olan etkileri"

çökelme, yağışlarla çökelme veya toprak yüzeyinde adsorbe edilme gibi yollarla ulaşırlar. Kirleticiler niteliklerine ve çevre koşullarına bağlı olarak toprakların fiziksel, kimyasal ve biyolojik özellikleri üzerine değişik etkiler oluştururlar. Bu etkiler sonucu toprak üzerinde bulunan kültür ve doğal bitki örtüsü de koşullara bağlı olarak değişik tepkiler veya zararlanmalar gösterebilirler (Haktanır, 1987).

Çepel ve Dündar (1983) tarafından SarnsunGelemen yöresinde yapılan bir araştırma sonucuna göre fabrika bacalarından salınan $\mathrm{SO}_{2}$ gazının topraklarda henüz belirgin bir zarara yol açmadığı, ancak kireçce fakir ve kireçsiz topraklara toprak reaksiyonu $(\mathrm{pH})$ açısından kritik sınıra yaklaşıldığı ve ileride zararlı etkilerin başlayabileceği ifade edilmektedir. Topraktaki asitliğin atmosfere atılan $\mathrm{SO}_{2}$ gazının asit yağışı ile toprağa dönerek yükseldiği, bundan toprak mikroorganizmalarının olumsuz yönde etkilenerek toprak verimliliğinin azaldığı Oruç ve Kırımhan (1984) tarafından bildirilmektedir.

$\mathrm{Bu}$ araştırmanın amacı, Samsun Azot Sanayii (TÜGSAŞ) ve Karadeniz Bakır Işletmeleri (KBI) baca emisyonlarının çevredeki tarım topraklarının bazı kimyasal ve biyolojik özellikleri ile bazı ağır metallerin ( $\mathrm{Fe}, \mathrm{Cu}, \mathrm{Zn}$, $\mathrm{Mn})$ miktarına olan etkilerinin araştırılmasıdır.

\section{Materyal ve Yöntem}

Araştırma alanı, Samsun Azot Sanayii (TÜGSAŞ) ve Karadeniz Bakır Işletmeleri (KBl) fabrikaları çevresidir. Her iki fabrika birbirine çok yakında $(50-100 \mathrm{~m})$ olup, aynı saha içinde bulunmaktadırlar. Doğu ve Güneydoğu yönündeki Çarşamba ovası yöredeki en büyük tarımsal alandır. Güneyde ise Tekkeköy ve Aşağı Çinik ovaları ve daha yüksek yamaç kesimlerinde yer alan tütün alanları bulunmaktadır. Fabrikaların batı kesiminde alüviyal düz alanlar yer almaktadır.

Devlet Meteoroloji Işleri Genel Müdürlüğü kayıtlarına göre bölgedeki yıllık ortalama nispi nem \% 72 olup en hızlı rüzgar kuzey batıdan esmektedir. Hakim rüzgar yönü ise yılın 12 ayında da kuzey-güney doğrultusundadır.

Bölgedeki hakim rüzgar yönü ve tarımsal alanların yayılma durumu dikkate alınarak üç ayrı doğrultuda toprak örneklemesi yapılmıştır. Fabrikalara 11 ayrı uzaklık ve üç doğrultudaki noktalardan alınan toprak örnekleme noktaları merkeze yakalştıkça sıklaşmaktadır. Örnekleme noktalarının fabrika bacalarına olan uzaklıkları 0.5-1.0-1.52.0-2.5-3.0-6.0-9.0-12.0-15.0-30.0 km'dir. Toprak örneklerinin alındığı derinlikler ise $0-5,5-10,10-20,20-40$, 40-60, 60-80 cm'dir. Toprak örneklerinin alındığı yönler ise güney batı (I), doğu (II) ve güney doğu (III) doğrultusudur.

Alınan toprak örneklerinde toprak reaksiyonu $\mathrm{pH}$ saturasyon çamurunda cam elektrotlu $\mathrm{pH}$ metre ile
(Richards, 1954) kireç kapsamı Çağlar (1958)'e göre Scheibler kalsimetresi ile, toprak tekstürü Bouyoucos (1951) hidrometre yöntemine, edilebilir $\mathrm{Fe}, \mathrm{Cu}, \mathrm{Zn}, \mathrm{Mn}$ Lindsay ve Norwel (1978)'in bildirdiği şekilde Atomik Absorbsiyon Spektrofotometre (Perkin-Elmer 2280) ile belirlenmiştir. Toprakların biyolojik özelliklerini belirlemek için yapılan $\mathrm{CO}_{2}$ üretimi ölçümü Isermeyer (1952)'e, dehidrogenaz (DHG) enzim aktivitesi ise Thalmann (1967)'a göre belirlenmiştir.

\section{Bulgular ve Tartışma}

Samsun Azot Sanayii (TÜGSAŞ) ve Karadeniz Bakır İşletmeleri (KBI) fabrikalarından üç ayrı yönde ve farklı uzaklıktaki alanlardan alınan toprakların $\mathrm{pH}$ değerleri hafif asit ve hafif alkali (6.1-8.2) reaksiyon arasinda değişmektedir. Toprakların $\mathrm{pH}$ değerleri değişken bir dağılım göstermektedir (Çizelge 1). Toprakların tamamı alüviyal olan, doğu yönündeki örneklerin $\mathrm{pH}$ değerleri diğer yönlere göre biraz daha yüksek bulunmuştur. Fabrika uzaklığı ile toprakiarın $\mathrm{pH}$ değerleri arasında bir ilişki belirlenememiştir. Alınan toprak örneklerinin kireç kapsamının genelde çok düșük olduğu, profil boyunca toprak derinliğinin artmasıyla kireç kapsamının azaldığı ve fabrika uzaklığı ile toprakların kireç kapsamı arasında bir ilşiki olmadığı belirlenmiştir (Çizelge 1). Benzer sonuçlar Çepel ve Dündar (1983) tarafından Samsun-Gelemen yöresinde yapılan bir araştırma ile saptanmıştır. Fabrika bacalarından çıkan emisyonların çevre toprakları üzerine etkilerini saptayabilmek amacıyla incelenen biyolojik kriterler toprağın $\mathrm{CO}_{2}$ üretimi ve dehidrogenaz (DHG) enzim aktivitesidir. Alınan toprak örneklerinde yapilan analizler sonucunda biyolojik parametrelerin fabrikadan uzaklık ve yöne bağlı olarak karakteristik bir dağılım göstermedikleri ortaya konmuştur. Biyolojik kriterlerden dehidrogenaz enzim aktivitesi değerlerinin fabrikalara yakın alanlarda yüksek olduğu saptanmıştır (Çizelge 2). Bu sonuçlar Haktanır (1983)'ın elde ettiği bulgulara benzerlik göstermektedir.

Topraklarda analizi yapılan alınabilir ağır metallerle $\mathrm{Fe}, \mathrm{Cu}, \mathrm{Zn}$, ve $\mathrm{Mn}$, konsantrasyonlarının fabrikalara yakın alanlarda yüksek olduğu ve toprak derinliğinin artmasıyla azaldığı ortaya konmuştur. Toprak yüzeyinde belirlenen ağır metal birikiminin özellikle hakim rüzgar yönü olan Güney doğu (III) ve doğu (II) yönlerinde daha fazla olduğu saptanmıştır (Çizelge 1). Benzer sonuçlar Zabunoğlu (1989) tarafından da belirlenmiştir.

Zabunoğlu ve ark' nın (1989) Samsun Azot Sanayii ve Karadeniz Bakır Işletmeleri baca emisyonlarının çevredeki tarım alanlarına ve bitkisel ürüne etkilerini araştırdıkları çalışma sonucunda, fabrikadan $3.6 \mathrm{~km}$ uzaklıklarda toprakta $\mathrm{Fe}$ ve $\mathrm{Cu}$ birikimi olduğu, toprak yüzeyinde asitleşme eğilimi olduğu, ancak toprak mikroflorası üzerinde herhangi bir olumsuz etkinin olmadığı saptanmıştır. 
Çizelge 1. Samsun Azot Sanayii ve KBi Fabrikalarında 3 ayrı yönde ve farklı uzaklıktaki alanlardan alınan toprakların bazı özellikleri

\begin{tabular}{|c|c|c|c|c|c|c|c|c|c|}
\hline $\begin{array}{l}\text { Örnek } \\
\text { No }\end{array}$ & $\begin{array}{l}\text { Toprak } \\
\text { derinliği } \\
\text { (cm) }\end{array}$ & $\begin{array}{c}\mathrm{pH} \\
\text { (Sat.C.) }\end{array}$ & $\begin{array}{c}\text { Kireç } \\
\left(\% \mathrm{CaCO}_{3}\right)\end{array}$ & $\begin{array}{c}\text { Tekstür } \\
\text { sinifi }\end{array}$ & - & $\underline{\mathrm{Cu}}$ & $\begin{array}{l}\text { Alinabili } \\
\mathrm{Zn} \\
\mathrm{ppm} \\
\end{array}$ & $\mathrm{Mn}$ & $\mathrm{Fe}$ \\
\hline I/1 & $0-20$ & 7.7 & 0.0 & $\mathrm{~L}$ & & 2.56 & 0.61 & 5.56 & 31.82 \\
\hline $1 / 1$ & $20-40$ & 7.6 & 1.96 & $\mathrm{~L}$ & & 2.89 & 0.44 & 6.20 & 30.01 \\
\hline $1 / 1$ & $40-60$ & 7.5 & 1.34 & $\mathrm{~L}$ & & 2.12 & 0.37 & 5.87 & 29.08 \\
\hline $1 / 1$ & $60-80$ & 7.8 & 1.07 & L & & 1.90 & 0.21 & 5.12 & 25.4 \\
\hline $1 / 2$ & $0-20$ & 7.1 & 1.34 & $S$ & & 5.4 & 2.6 & 10.28 & 35.2 \\
\hline $1 / 2$ & $20-40$ & 6.7 & 1.07 & $S$ & & 6.7 & 1.9 & 8.36 & 32.89 \\
\hline $1 / 2$ & $40-60$ & 6.7 & 0.89 & $\mathrm{~S}$ & & 3.8 & 1.74 & 7.38 & 29.01 \\
\hline $1 / 2$ & $60-80$ & 6.4 & $0.0-$ & $\mathrm{S}$ & & 2.4 & 1.02 & 5.4 & 29.0 \\
\hline 1/3 & $0-20$ & 6.8 & 2.14 & L & & 2.52 & 0.42 & 17.93 & 37.05 \\
\hline $1 / 3$ & $20-40$ & 6.8 & 0.0 & $\mathrm{~L}$ & & 2.39 & 0.22 & 12.72 & 27.76 \\
\hline $1 / 3$ & $40-60$ & 6.7 & 0.45 & $\mathrm{~L}$ & & 2.38 & 0.26 & 11.81 & 18.77 \\
\hline $1 / 3$ & $60-80$ & 6.3 & 0.98 & $\mathrm{~L}$ & & 2.37 & 0.24 & 11.81 & 14.33 \\
\hline $1 / 4$ & $0-20$ & 6.8 & 0.0 & $S$ & & 2.72 & 0.38 & 20.83 & 27.76 \\
\hline $1 / 4$ & $20-40$ & 6.3 & 0.8 & $\mathrm{~S}$ & & 2.57 & 0.29 & 13.13 & 19.64 \\
\hline $1 / 4$ & $40-60$ & 6.3 & 0.8 & $\mathrm{~S}$ & & 2.37 & 0.27 & 9.08 & 30.47 \\
\hline $1 / 4$ & $60-80$ & 6.2 & 0.8 & $\mathrm{~S}$ & & 0.06 & 0.24 & 3.8 & 42.56 \\
\hline $1 / 5$ & $0-20$ & 7.3 & 0.0 & $L$ & & 2.99 & 2.85 & 9.99 & 17.6 \\
\hline $1 / 5$ & $20-40$ & 7.3 & 0.0 & $L$ & & 2.71 & 1.55 & 7.2 & 26.6 \\
\hline $1 / 5$ & $40-60$ & 7.4 & 0.0 & $L$ & & 2.56 & 0.56 & 7.54 & 26.89 \\
\hline $1 / 5$ & $60-80$ & 7.5 & 0.0 & $L$ & & 2.37 & 0.43 & 5.61 & 16.74 \\
\hline $1 / 6$ & $0-20$ & 6.3 & 0.0 & $L$ & & 4.48 & 1.18 & 15.32 & 54.46 \\
\hline 1/6 & $20-40$ & 6.8 & 0.54 & $L$ & & 3.98 & 0.97 & 24.44 & 70.41 \\
\hline $1 / 6$ & $40-60$ & 7.1 & 0.0 & $L$ & & 2.7 & 0.59 & 20.1 & 33.57 \\
\hline $1 / 6$ & $60-80$ & 7.3 & 0.0 & $L$ & & 1.27 & 0.48 & 5.62 & 29.64 \\
\hline $1 / 7$ & $0-20$ & 7.1 & 0.0 & $S$ & & 3.45 & 1.07 & 8.16 & 12.68 \\
\hline $1 / 7$ & $20-40$ & 7.5 & 2.07 & $\mathrm{~S}$ & & 3.96 & 0.96 & 12.16 & 31.54 \\
\hline $1 / 7$ & $40-60$ & 6.1 & 1.96 & $\mathrm{~S}$ & & 4.00 & 0.82 & 6.73 & 27.47 \\
\hline $1 / 7$ & $60-80$ & 6.1 & 0.45 & $S$ & & 3.04 & 0.09 & 3.37 & 30.08 \\
\hline $1 / 8$ & $0-20$ & 7.1 & 0.8 & L & & 4.15 & 1.15 & 8.16 & 30.67 \\
\hline $1 / 8$ & $20-40$ & 7.2 & 0.0 & $\mathrm{~L}$ & & 4.58 & 0.75 & 12.15 & 35.6 \\
\hline $1 / 8$ & $40-60$ & 7.4 & 0.45 & $L$ & & 3.07 & 0.27 & 10.17 & 40.5 \\
\hline $1 / 8$ & $60-80$ & 7.4 & 0.38 & $\mathrm{~L}$ & & 3.05 & 0.24 & 10.1 & 40.3 \\
\hline $1 / 9$ & $0-20$ & 7.2 & 0.0 & $\mathrm{~L}$ & & 3.8 & 0.9 & 6.84 & 50.86 \\
\hline 1/9 & $20-40$ & 7.4 & 0.45 & $L$ & & 3.2 & 0.5 & 7.67 & 48.65 \\
\hline 1/9 & $40-60$ & 7.2 & 0.84 & $L$ & & 3.0 & 0.53 & 6.04 & 30.95 \\
\hline $11 / 2$ & $0-20$ & 7.6 & 19.09 & L & & 4.13 & 1.38 & 3.21 & 14.13 \\
\hline $11 / 2$ & $20-40$ & 7.9 & 20.5 & $L$ & & 4.20 & 0.29 & 1.92 & 16.16 \\
\hline $11 / 2$ & $40-60$ & 8.0 & 1.16 & $\mathrm{~L}$ & & 1.62 & 0.23 & 1.53 & 19.06 \\
\hline 1112 & $60-80$ & 8.1 & 1.69 & $L$ & & 2.37 & 0.19 & 0.6 & 8.04 \\
\hline $11 / 3$ & $0-20$ & 7.8 & 12.93 & $\mathrm{~L}$ & & 4.05 & 0.58 & 7.38 & 43.14 \\
\hline $11 / 3$ & $20-40$ & 7.9 & 0.89 & $\mathrm{~L}$ & & 3.71 & 0.24 & 5.12 & 63.15 \\
\hline $11 / 3$ & $40-60$ & 7.6 & 0.89 & $\mathrm{~L}$ & & 3.59 & 0.01 & 7.16 & 54.16 \\
\hline $11 / 3$ & $60-80$ & 8.2 & 1.43 & $L$ & & 2.49 & 0.08 & 3.08 & 17.16 \\
\hline $11 / 4$ & $0-20$ & 7.8 & 2.14 & $L$ & & 3.47 & 0.07 & 3.30 & 22.84 \\
\hline $11 / 4$ & $20-40$ & 7.8 & 0.54 & $\mathrm{CL}$ & & 2.5 & 1.0 & 3.5 & 21.47 \\
\hline $11 / 4$ & $40-60$ & 8.0 & 3.12 & L & & 1.56 & 0.06 & 3.74 & 20.5 \\
\hline $11 / 4$ & $60-8$ & 8.1 & 16.5 & $L$ & & 1.02 & 0.0 & 3.42 & 13.26 \\
\hline $11 / 5$ & $0-20$ & 7.8 & 29.8 & $L$ & & 3.21 & 0.58 & 3.17 & 45.46 \\
\hline $11 / 5$ & $40-60$ & 7.7 & 20.5 & $L$ & & 3.75 & 0.17 & 2.27 & 44.62 \\
\hline
\end{tabular}


KARA, E.E. ve ark. "Samsun Azot Sanayii (TÜGSAŞ) ve Karadeniz Bakır Ișletmesi (KBi) emisyonlarının çevre topraklarına olan etkileri"

Çizelge 1. (Devamı) Samsun Azot Sanayii ve KBi Fabrikalarında 3 ayrı yönde ve farklı uzaklıktaki alanlardan alınan toprakların bazı özellikleri

\begin{tabular}{|c|c|c|c|c|c|c|c|c|}
\hline $\begin{array}{l}\text { Örnek } \\
\text { No }\end{array}$ & $\begin{array}{c}\text { Toprak } \\
\text { derinliği } \\
(\mathrm{cm})\end{array}$ & $\begin{array}{c}\mathrm{pH} \\
\text { (Sat.C.) }\end{array}$ & $\begin{array}{l}\text { Kireç } \\
\left(\% \mathrm{CaCO}_{3}\right)\end{array}$ & $\begin{array}{l}\text { Tekstür } \\
\text { sinıfi }\end{array}$ & $\underline{\mathrm{Cu}}$ & $\begin{array}{c}\begin{array}{c}\text { Alınabil } \\
\mathrm{Zn}\end{array} \\
\mathrm{ppm}\end{array}$ & $\mathrm{Mn}$ & $\mathrm{Fe}$ \\
\hline $11 / 5$ & $60-80$ & 7.6 & 0.71 & L & 1.33 & 0.55 & 4.90 & 39.4 \\
\hline $1 / 5$ & $20-40$ & 7.7 & 34.45 & $L$ & 3.68 & 0.55 & 4.52 & 34.44 \\
\hline $11 / 6$ & $0-20$ & 7.6 & 15.6 & L & 3.00 & 0.71 & 2.95 & 20.51 \\
\hline \begin{tabular}{|l|l|}
$11 / 6$ \\
\end{tabular} & $20-40$ & 7.5 & 25.86 & L & 1.66 & 0.76 & $4 . \overline{11}$ & 25.44 \\
\hline $11 / 6$ & $40-60$ & 7.6 & 36.6 & $L$ & 3.03 & 0.57 & 4.52 & 24.3 \\
\hline $11 / 6$ & $60-80$ & 8.2 & 1.34 & $L$ & 2.7 & 0.34 & 3.8 & 17.6 \\
\hline $111 / 7$ & $0-20$ & 7.8 & 25.33 & $L$ & 21.68 & 1.47 & 3.2 & 12.82 \\
\hline $111 / 7$ & $20-40$ & 7.6 & 0.89 & L & 3.45 & 0.71 & 0.38 & 28.06 \\
\hline 1117 & $40-60$ & 7.9 & 0.45 & $L$ & 2.95 & 0.18 & 3.4 & 25.16 \\
\hline 1117 & $60-80$ & 8.0 & 2.49 & $L$ & 2.50 & 0.15 & 3.82 & 24.15 \\
\hline III/8 & $0-20$ & 7.9 & 26.93 & $L$ & 4.13 & 0.31 & 5.23 & 24.87 \\
\hline $11 / 8$ & $20-40$ & 7.5 & 1.78 & $\mathrm{~L}$ & 2.98 & 0.12 & 6.64 & 30.67 \\
\hline $11 / 8$ & $40-60$ & 7.4 & 1.07 & $\mathrm{~L}$ & 3.01 & 0.13 & 15.70 & 35.89 \\
\hline $11 / 8$ & $60-80$ & 8.0 & 1.34 & $L$ & 2.78 & 0.14 & 10.56 & 30.08 \\
\hline \begin{tabular}{|l|l|}
$11 / 9$ \\
\end{tabular} & $0-20$ & 7.7 & 3.57 & $S$ & 3.51 & 0.6 & 3.44 & 19.64 \\
\hline \begin{tabular}{|l|}
$11 / 9$ \\
\end{tabular} & $20-40$ & 7.7 & 0.89 & $S$ & 2.77 & 0.23 & 3.88 & 30.96 \\
\hline $11 / 9$ & $40-60$ & 7.8 & 2.76 & $\mathrm{~S}$ & 1.65 & 0.25 & 8.28 & 29.74 \\
\hline $11 / 9$ & $60-80$ & 7.8 & 1.34 & $\mathrm{~L}$ & 3.14 & 0.18 & 7.51 & 35.83 \\
\hline $11 / 10$ & $0-20$ & 7.7 & 2.14 & $L$ & 3.27 & 0.7 & 2.04 & 15.3 \\
\hline $11 / 10$ & $20-40$ & 7.7 & 0.89 & $L$ & 2.88 & 0.25 & 2.24 & 7.46 \\
\hline $11 / 10$ & $40-60$ & 8.2 & 0.178 & $\mathrm{~S}$ & 2.68 & 0.14 & 7.77 & 20.2 \\
\hline $11 / 10$ & $60-80$ & 7.7 & 0.0 & $S$ & 2.34 & 0.05 & 6.35 & 9.78 \\
\hline $11 / 11$ & $0-20$ & 8.0 & 0.71 & $\mathrm{~S}$ & 3.24 & 0.3 & 5.19 & 27.19 \\
\hline $11 / 11$ & $20-40$ & 8.2 & 0.0 & $S$ & 3.46 & 0.19 & 5.9 & 55.3 \\
\hline $11 / 11$ & $40-60$ & 8.2 & 8.92 & $\mathrm{~s}$ & 0.21 & 0.0 & 5.55 & 10.07 \\
\hline III/11 & $60-80$ & 8.3 & 0.71 & $\mathrm{~S}$ & 2.37 & 0.18 & 5.16 & 10.94 \\
\hline IIII/1 & $0-20$ & 7.1 & 1.07 & $L$ & 3.81 & 0.51 & 2.132 & 1.67 \\
\hline $1111 / 1$ & $20-40$ & 7.5 & 0.89 & $L$ & 2.87 & 0.47 & 2.0 & 21.2 \\
\hline $111 / 1$ & $40-60$ & 7.7 & 0.0 & $L$ & 2.7 & 0.3 & 1.87 & 15.7 \\
\hline IIII/1 & $60-80$ & 8.2 & 0.0 & $L$ & 2.2 & 0.0 & 0.92 & 13.3 \\
\hline $111 / 2$ & $0-20$ & 7.5 & 7.13 & $L$ & 3.14 & 0.15 & 2.43 & 20.51 \\
\hline III/2 & $20-40$ & 7.7 & 1.78 & $L$ & 3.27 & 0.11 & 72 & 35.3 \\
\hline $111 / 2$ & $40-60$ & 7.7 & 1.52 & $\mathrm{CL}$ & 3.94 & 0.32 & 6.65 & 20.4 \\
\hline $111 / 2$ & $60-80$ & 8.0 & 1.34 & $\mathrm{~L}$ & 2.99 & 0.31 & 8.55 & 18.48 \\
\hline $111 / 3$ & $0-20$ & 7.4 & 0.89 & $L$ & 3.83 & 0.64 & 9.83 & 31.83 \\
\hline $111 / 3$ & $20-40$ & 7.6 & 0.8 & $\mathrm{~L}$ & 3.62 & 0.57 & 8.7 & 31.6 \\
\hline $1111 / 3$ & $40-60$ & 7.7 & 0.89 & $\mathrm{~L}$ & 3.27 & 0.25 & 7.95 & 32.99 \\
\hline $111 / 3$ & $60-80$ & 7.4 & 0.89 & L & 3.64 & 0.2 & 5.01 & 28.05 \\
\hline
\end{tabular}


Çizelge 1. (Devamı) Samsun Azot Sanayii ve KBI Fabrikalarında 3 ayrı yönde ve farklı uzaklıktaki alanlardan alınan toprakların bazı özellikleri

\begin{tabular}{|c|c|c|c|c|c|c|c|c|}
\hline $\begin{array}{l}\text { Örnek } \\
\text { No }\end{array}$ & $\begin{array}{l}\text { Toprak } \\
\text { derinliği } \\
(\mathrm{cm})\end{array}$ & $\begin{array}{c}\mathrm{pH} \\
\text { (Sat.C.) }\end{array}$ & $\begin{array}{c}\text { Kireç } \\
\left(\% \mathrm{CaCO}_{3}\right)\end{array}$ & $\begin{array}{l}\text { Tekstür } \\
\text { sinifi }\end{array}$ & $\underline{\mathrm{Cu}}$ & $\begin{array}{l}\text { Alınabilir } \\
\mathrm{Zn} \\
\mathrm{ppm} \\
\end{array}$ & $\mathrm{Mn}$ & $\mathrm{Fe}$ \\
\hline $1111 / 4$ & $0-20$ & 6.7 & 1.56 & $L$ & 3.23 & 0.27 & 0.72 & 27.76 \\
\hline $111 / 4$ & $20-40$ & 7.0 & 0.0 & $\mathrm{CL}$ & 3.96 & 0.36 & 7.67 & 30.67 \\
\hline $111 / 4$ & $0-20$ & 6.7 & 1.56 & $L$ & 3.23 & 0.27 & 0.72 & 27.76 \\
\hline $111 / 4$ & $20-40$ & 7.0 & 0.0 & $\mathrm{CL}$ & 3.96 & 0.36 & 7.67 & 30.67 \\
\hline $111 / 4$ & $40-60$ & 7.1 & 0.0 & $\mathrm{CL}$ & 3.8 & 0.32 & 7.5 & 26.8 \\
\hline $111 / 4$ & $60-80$ & 7.2 & 0.0 & $\mathrm{CL}$ & 2.7 & 0.35 & 5.8 & 22.4 \\
\hline $111 / 5$ & $0-20$ & 7.7 & 15.07 & $L$ & 6.71 & 1.1 & 17.63 & 58.37 \\
\hline $111 / 5$ & $20-40$ & 8.0 & 0.89 & $L$ & 4.05 & 0.82 & 11.94 & 56.48 \\
\hline $111 / 5$ & $40-60$ & 8.0 & 0.89 & $L$ & 2.68 & 0.19 & 7.12 & 49.06 \\
\hline $111 / 5$ & $60-80$ & 8.1 & 1.43 & $L$ & 3.78 & 0.19 & 9.36 & 50.1 \\
\hline $111 / 6$ & $0-20$ & 7.5 & 0.0 & $L$ & 4.2 & 1.45 & 1.96 & 46.33 \\
\hline $111 / 6$ & $20-40$ & 7.5 & 1.16 & $L$ & 3.14 & 1.06 & 5.56 & 40.53 \\
\hline $111 / 6$ & $60-80$ & 7.5 & 1.25 & $S$ & 2.88 & 0.39 & 7.12 & 37.25 \\
\hline 11117 & $0-20$ & 7.8 & 0.0 & $L$ & 8.17 & 1.84 & 14.03 & 48.65 \\
\hline $111 / 7$ & $20-40$ & 7.7 & 0.0 & $\mathrm{C}$ & 3.68 & 0.53 & 7.77 & 28.93 \\
\hline $111 / 7$ & $40-60$ & 7.7 & 0.0 & C & 3.33 & 0.45 & 3.64 & 42.56 \\
\hline $111 / 7$ & $60-80$ & 7.7 & 5.35 & $\mathrm{CL}$ & 3.67 & 0.44 & 7.12 & 59.1 \\
\hline $111 / 8$ & $0-20$ & 7.6 & 4.9 & $L$ & 4.0 & 0.94 & 8.68 & 48.82 \\
\hline $111 / 8$ & $20-40$ & 7.7 & 4.45 & L & 4.5 & 0.92 & 8.54 & 47.54 \\
\hline $111 / 8$ & $40-60$ & 7.6 & 7.13 & $\mathrm{~L}$ & 4.95 & 0.91 & 8.44 & 53.58 \\
\hline $111 / 8$ & $60-80$ & 7.6 & 6.24 & $L$ & 20.05 & 0.84 & 7.89 & 45.34 \\
\hline $111 / 9$ & $0-20$ & 6.8 & 2.9 & $\mathrm{CL}$ & 11.7 & 2.0 & 9.47 & 46.33 \\
\hline $111 / 9$ & $20-40$ & 7.4 & 0.178 & $L$ & 11.5 & 1.94 & 13.99 & 65.77 \\
\hline $111 / 9$ & $40-60$ & 6.85 & 0.18 & $L$ & 3.17 & 0.71 & 14.42 & 43.14 \\
\hline $111 / 9$ & $60-80$ & 7.5 & 0.89 & $\mathrm{~L}$ & 2.93 & 0.36 & 17.93 & 49.82 \\
\hline $111 / 10$ & $0-20$ & 6.8 & 1.78 & $L$ & 9.06 & 1.6 & 14.68 & 38.79 \\
\hline $111 / 10$ & $20-40$ & 7.2 & 0.89 & $L$ & 12.66 & 1.86 & 19.7 & 20.8 \\
\hline $111 / 10$ & $40-60$ & 6.7 & 1.115 & $L$ & 4.96 & 2.36 & 20.54 & 78.54 \\
\hline $111 / 10$ & $60-80$ & 6.9 & 2.14 & $L$ & 5.02 & 1.36 & 19.34 & 51.26 \\
\hline $111 / 11$ & $0-20$ & 6.2 & 0.0 & $\mathrm{CL}$ & 61.27 & 0.44 & 5.95 & 10.4 \\
\hline $\mid 11 / 11$ & $20-40$ & 6.9 & 0.8 & $L$ & 30.89 & 1.76 & 2.72 & 30.0 \\
\hline $111 / 11$ & $40-60$ & 6.6 & 0.45 & $\mathrm{~L}$ & 3.79 & 0.5 & 8.96 & 43.72 \\
\hline $111 / 11$ & $60-80$ & 7.5 & 0.09 & L & 1.85 & 0.4 & 11.24 & 11.23 \\
\hline
\end{tabular}


Çizelge 2. Samsun Azot Sanayii ve KBI Fabrikalarında 3 ayrı yönde ve farklı uzaklıktaki alanlardan alınan toprakların $\mathrm{CO}_{2}$ üretimi, dehidrogenaz aktivitesi değerleri

\begin{tabular}{|c|c|c|c|}
\hline $\begin{array}{c}\text { Örnek } \\
\text { No }\end{array}$ & $\begin{array}{l}\text { Toprak } \\
\text { derinliği } \\
(\mathrm{cm})\end{array}$ & $\begin{array}{c}\mathrm{CO}_{2} \text { Üretimi } \\
\mathrm{CO}_{2} / 100 \mathrm{~g} \\
\text { toprak } / 24 \mathrm{sa}\end{array}$ & $\begin{array}{l}\text { DHG Aktivitesi mg } \\
(\mathfrak{C}) \text { TPF } / 10 \mathrm{~g} \text { toprak }\end{array}$ \\
\hline $1 / 1$ & $0-5$ & 2.5 & 118 \\
\hline $1 / 1$ & $5-10$ & 1.2 & 250 \\
\hline $1 / 2$ & $0-5$ & 8.0 & 125 \\
\hline $1 / 7$ & $5-10$ & 2.7 & 113 \\
\hline $1 / 3$ & $0-5$ & 0.8 & 75 \\
\hline $1 / 3$ & $5-10$ & 0.5 & 125 \\
\hline $1 / 4$ & 0.5 & 7.4 & 117 \\
\hline $1 / 4$ & $5-10$ & 1.3 & 69 \\
\hline $1 / 5$ & $0-5$ & 0.5 & 225 \\
\hline $1 / 5$ & $5-10$ & 0.9 & 850 \\
\hline $1 / 6$ & $0-5$ & 15.7 & 163 \\
\hline $1 / 6$ & $5-10$ & 2.5 & 113 \\
\hline $1 / 7$ & 0.5 & 3.9 & 250 \\
\hline $1 / 7$ & $5-10$ & 3.5 & 100 \\
\hline $1 / 8$ & $0-5$ & 3.2 & 113 \\
\hline $1 / 8$ & $5-10$ & 2.1 & 150 \\
\hline $1 / 9$ & $0-5$ & 1.9 & 225 \\
\hline $1 / 9$ & $5-10$ & 2.7 & 225 \\
\hline $11 / 2$ & $0-5$ & 4.8 & 400 \\
\hline $11 / 2$ & 5.10 & 2.0 & 125 \\
\hline $11 / 3$ & $0-5$ & 3.0 & 400 \\
\hline $11 / 3$ & $5-10$ & 1.5 & 250 \\
\hline $1 / 4$ & $0-5$ & 5.4 & 263 \\
\hline $11 / 4$ & $5-10$ & 3.0 & 132 \\
\hline $11 / 5$ & $0-5$ & 4.6 & 302 \\
\hline $11 / 5$ & $5-10$ & 2.7 & 350 \\
\hline $11 / 6$ & $0-5$ & 2.5 & 563 \\
\hline $11 / 6$ & $5-10$ & 4.1 & 375 \\
\hline $11 / 7$ & 0.5 & 0.6 & 350 \\
\hline $11 / 7$ & $5-10$ & 1.4 & 420 \\
\hline $11 / 8$ & $0-5$ & 0.0 & 400 \\
\hline $11 / 8$ & $5-10$ & 0.0 & 250 \\
\hline $11 / 9$ & $0-5$ & 2.0 & 118 \\
\hline $11 / 9$ & $5-10$ & 9.6 & 662 \\
\hline $11 / 10$ & 0.5 & 2.3 & 437 \\
\hline $11 / 10$ & $5-10$ & 5.5 & 688 \\
\hline $11 / 11$ & 0.5 & 2.5 & 132 \\
\hline III11 & $5-10$ & 1.0 & 69 \\
\hline $111 / 1$ & $0-5$ & 5.3 & 113 \\
\hline $111 / 1$ & $5-10$ & 2.9 & 250 \\
\hline $111 / 2$ & $0-5$ & 4.4 & 263 \\
\hline $111 / 2$ & $5-10$ & 3.2 & 113 \\
\hline $111 / 3$ & $0-5$ & 5.4 & 100 \\
\hline $111 / 3$ & $5-10$ & 1.3 & 188 \\
\hline $111 / 4$ & $0-5$ & 2.2 & 113 \\
\hline $111 / 4$ & $5-10$ & 4.4 & 300 \\
\hline $111 / 5$ & $0-5$ & 0.3 & 75 \\
\hline $111 / 5$ & $5-10$ & 12.3 & 63 \\
\hline $111 / 6$ & $0-5$ & 0.8 & 36 \\
\hline $111 / 6$ & $5-10$ & 4.5 & 158 \\
\hline $111 / 7$ & $0-5$ & 0.1 & 113 \\
\hline $111 / 7$ & $5-10$ & 6.9 & 250 \\
\hline $111 / 8$ & $0-5$ & 21.6 & 324 \\
\hline $111 / 8$ & $5-10$ & 6.5 & 488 \\
\hline
\end{tabular}

Çizelge 2. (Devamı)i Samsun Azot Sanayii ve KBi Fabrikalarında 3 ayrı yönde ve farkı uzaklıktaki alanlardan alınan toprakların $\mathrm{CO}_{2}$ üretimi, dehidrogenaz aktivitesi değerleri

\begin{tabular}{|c|c|c|c|}
\hline $\begin{array}{c}\text { Örnek } \\
\text { No }\end{array}$ & $\begin{array}{c}\text { Toprak } \\
\text { derinliği } \\
(\mathrm{cm})\end{array}$ & $\begin{array}{c}\mathrm{CO}_{2} \text { Üretimi } \\
\mathrm{CO}_{2} / 100 \mathrm{~g} \\
\text { toprak/24 sa }\end{array}$ & $\begin{array}{c}\text { DHG Aktivitesi } \\
\mathrm{mg} \text { TPF/10 g } \\
\text { toprak }\end{array}$ \\
\hline $\mathrm{III/9}$ & $0-5$ & 4.2 & 125 \\
\hline $\mathrm{III} / 9$ & $5-10$ & 0.0 & 225 \\
\hline $\mathrm{III/10}$ & $0-5$ & 8.2 & 250 \\
\hline $\mathrm{III/10}$ & $5-10$ & 3.1 & 375 \\
\hline $\mathrm{III/11}$ & $0-5$ & 22.2 & 183 \\
\hline $\mathrm{III} / 11$ & $5-10$ & 8.3 & 298 \\
\hline
\end{tabular}

\section{Sonuç}

Samsun Azot Sanayii (TÜGSAŞ) ve Karadeniz Bakır Işletmeleri (KBI) çevresinde yapılan bu araştırma sonucuna göre; fabrika uzaklığı ile toprakların $\mathrm{pH}$ değerleri arasında bir ilişki olmadıği, toprak derınliğine bağlı olarak pH'da artış olduğu saptanmıştır.

Toprakların kireç kapsamı ile fabrika uzaklığı arasında bir ilişki olmadığı, kireç kapsamının genelde çok düşük olduğu ve profilde derinliğe bağlı olarak kireç kapsamının azaldığı belirlenmiştir.

Toprağın biyolojik özelliklerini belirlemede kullanılan kriterlerden $\mathrm{CO}_{2}$ üretimi ve dehidrogenaz (DHG) enzim aktivitesinin fabrikadan uzaklık ve yöne bağlı olarak karakteristik bir dağılım göstermediği, dehidrogenaz enzim aktivitesinin fabrikalara yakın alanlarda daha yüksek olduğu belirlenmiştir.

Fabrikalara yakın kesimlerde toprak yüzeyinde $\mathrm{Fe}$, $\mathrm{Cu}, \mathrm{Zn}, \mathrm{Mn}$ birikmesi olduğu, bu birikimin Güneydoğu ve Doğu yönündeki topraklarda daha fazla olduğu saptanmıştır.

Sonuç olarak Samsun Azot Sanayii (TÜGSAŞ) ve Karadeniz Bakır Işletmeleri (KBI) baca gazlarından çıkan emisyonların çevre topraklarına kirletici bir etki yaptığı, topraktaki kalıntı kirleticilerin miktarlarının yüzey katlarında fazla olduğu, özellikle $\mathrm{Fe}, \mathrm{Cu}, \mathrm{Zn}$ ve $\mathrm{Mn}$ birikimine neden olduğunu söyleyebiliriz.

\section{Kaynaklar}

Bouyouces, G.J-., 1951. A Recalibration of the Hydrometer Method for Making Mechanical Analysis of Soil. Agron. J., 43, 434-438

Çağlar, K.Ö., 1958. Toprak İımi. Ankiara Üniversitesi Yayınları. No:10 Ankara

Çepel, N., Dündar, M., 1983. Karadeniz Bakır Iş̧letmeleri ve Azot Sanayii Fabrikalarından Çıkan Kükürt Dioksit Gazının Yöredeki Toprakların Asitleşmesi Üzerine Etkisi. I. U. Orman Fakültesi Dergisi, Seri A, Cilt 33, Sayı1. 
Haktanır,K., 1987.Toprak Kirliliği ve Bu Konuda Hazırlanacak Yönetmelik Üzerine Düşünceler. Çalışma Grubu Raporu 2. TÇSV Yayını-Ankara.

Isermeyer. H., 1952. Eine Eingache Methode zur Bestimmung Der Bodenatmung und Karbonate in Boden. $Z$. Pflanzenernahrung. Dungung and Bodenkunde. 56, 2628 .

Kloke,A., 1980. Orientierungsdaten für Tolerierbare Gesamtgehalte Einiger Elemente in Kulturboden. Mitt.VDLUFAH.1,9-11.

Lindsay, W.L., Norwell, W.A., 1978 . Development of a DTPA Soil Test for zinc, iron, manganese and copper. Soil Sci. Soc. Am. J. 42:421-428.

Oruç, N., 1980. Tehlikeli Bir Çevre Sorunu; Asit Yağış Bölgesel Cevre Sorunları Simpozyumu Bildiri Özetleri. Atatürk Üniversitesi, Çevre Sorunları Araştırma Enstitüsü.19.
Oruc, N., S. Kırımhan, 1984. A preliminary study on the distribution of soil fluori des near on airborne flouredisource. V. Türk-Alrnan Çevre Müh. Semp., 11-16 Haziran. Dokuz Eylül Üniv. Mühendislik-MimarlikFak. Çevre Müh. Böl. İzmir.

Richards, L.A., 1954. Diagnosis and Improvement Saline and Alkaline Soils. U.S. Dep. Agr. Handbook 60.

Thalmann, A., 1967. Uber die mikrobielle Aktivitat und ihre Beziehungen $\mathrm{Zu}$ Fruchtbarke smerkmalen einiger Ackerböden unter beson derer Berücksichtigung der Dehydrogenase aktivitat (TTC-Reduction) Diss-Giessen.

Zabunoğlu, S., Haktanır., I. Karacia, I., K. Oskay., 1989. Samsun Azot Sanayii ve Karadeniz Bakır Işletıneleri Baca Emisyonlarının Çevredeki Tarım Alanlarına ve Bitkisel Ürüne Etkilerinin Araştırılması, TÜBITAK Proje No: ÇAĞ84. 